\title{
A model of the costs of community and nosocomial pediatric respiratory syncytial virus infections in Canadian hospitals
}

\author{
Philip Jacobs $\mathrm{PhD}^{1}$, Douglas Lier $\mathrm{MA}^{2}$, Katherine Gooch PhD MAppEpi ${ }^{3}$, Katharina Buesch ${ }^{4}$, \\ Michelle Lorimer $\mathrm{BSC}^{5}$, lan Mitchell MBChB MA DCH MRCP(UK) FRCPC FCCP6
}

P Jacobs, D Lier, K Gooch, K Buesch, M Lorimer, I Mitchell. A model of the costs of community and nosocomial pediatric respiratory syncytial virus infections in Canadian hospitals. Can J Infect Dis Med Microbiol 2013;24(1):22-26.

BACKGROUND: Approximately one in 10 hospitalized patients will acquire a nosocomial infection (NI) after admission to hospital, of which $71 \%$ are due to respiratory viruses, including the respiratory syncytial virus (RSV). NIs are concerning and lead to prolonged hospitalizations. The economics of NIs are typically described in generalized terms and specific cost data are lacking.

OBJECTIVE: To develop an evidence-based model for predicting the risk and cost of nosocomial RSV infection in pediatric settings.

METHODS: A model was developed, from a Canadian perspective, to capture all costs related to an RSV infection hospitalization, including the risk and cost of an NI, diagnostic testing and infection control. All data inputs were derived from published literature. Deterministic sensitivity analyses were performed to evaluate the uncertainty associated with the estimates and to explore the impact of changes to key variables. A probabilistic sensitivity analysis was performed to estimate a confidence interval for the overall cost estimate.

RESULTS: The estimated cost of nosocomial RSV infection adds approximately $30.5 \%$ to the hospitalization costs for the treatment of community-acquired severe RSV infection. The net benefits of the preRSV-related costs. Changes in the estimated hospital infection transmission rates did not have a significant impact on the base-case estimate. CONCLUSIONS: The risk and cost of nosocomial RSV infection contributes to the overall burden of RSV. The present model, which was developed to estimate this burden, can be adapted to other countries with different disease epidemiology, costs and hospital infection transmission rates.

Key Words: Nosocomial infection; Pediatrics; Respiratory syncytial virus vention activities were estimated to be equivalent to $9 \%$ of the total

\author{
Un modèle du coût des infections par le virus \\ respiratoire syncytial d'origine non nosocomiale et \\ nosocomiale en pédiatrie dans les hôpitaux \\ canadiens
}

HISTORIQUE : Environ un patient hospitalisé sur dix contractera une infection d'origine nosocomiale (ION) après son hospitalisation, dont $71 \%$ sont imputables à des virus respiratoires, y compris le virus respiratoire syncytial (VRS). Les ION sont inquiétantes et provoquent des hospitalisations prolongées. En général, les aspects économiques des ION sont décrits en termes généraux, et on ne possède pas de données précises sur leurs coûts.

OBJECTIF : Élaborer un modèle fondé sur des données probantes pour prédire le risque et le coût des infections à VRS d'origine nosocomiale en milieu pédiatrique.

MÉTHODOLOGIE : Les chercheurs ont élaboré un modèle, d'après une perspective canadienne, afin de saisir tous les coûts liés à une hospitalisation découlant d'une infection à VRS, y compris le risque et le coût d'une ION, les tests diagnostiques et le contrôle de l'infection. Toutes les données saisies étaient dérivées des publications. Les chercheurs ont effectué des analyses de sensibilité déterministe pour évaluer l'incertitude associée aux évaluations et pour explorer les répercussions de changements aux variables clés. Ils ont effectué une analyse de sensibilité probabiliste pour évaluer l'intervalle de confiance de l'évaluation globale des coûts.

RÉSULTATS : Les coûts estimatifs de l'infection à VRS d'origine nosocomiale ajoutent environ 30,5\% aux frais d'hospitalisation pour traiter l'infection à VRS grave d'origine non nosocomiale. Les chercheurs ont évalué que les bénéfices nets des activités de prévention équivalaient à $9 \%$ des coûts totaux liés au VRS. Les modifications aux taux estimatifs de transmission de l'infection en milieu hospitalier n'avaient pas de répercussions significatives sur l'évaluation des cas de base.

CONCLUSIONS : Le risque et le coût de l'infection à VRS d'origine nosocomiale contribuent au fardeau global du VRS. Le présent modèle, qui a été élaboré pour évaluer ce fardeau, peut être adapté à d'autres pays selon d'autres épidémiologies de maladies, coûts et taux de transmission de l'infection en milieu hospitalier.

$\mathrm{H}$ uman respiratory syncytial virus (RSV) is an important cause of viral lower respiratory tract infection in infants and children, and is associated with substantial morbidity and mortality (1-3). In an economic analysis of RSV infection in Canadian hospitals, Langley et al (4) found that $0.75 \%$ of Canadian infants ( $\leq 12$ months of age) were hospitalized with RSV-related bronchiolitis, with an average hospital stay of 6.7 days and an annual national cost of $\$ 18$ million. Schanzer et al (5) estimated the pediatric hospitalization rate attributable to RSV to be 130 admissions per 100,000 children and adolescents between zero and 19 years of age $(0.13 \%)$. This estimate, which took into consideration the impact of other respiratory viruses, was based on a model of pediatric hospital admissions from 1994 to 2000. The authors concluded that $10 \%$ of all pediatric admissions could be attributed to RSV, with the

${ }^{1}$ Department of Medicine, University of Alberta; ${ }^{2}$ Institute of Health Economics, Edmonton, Alberta; ${ }^{3}$ Abbott Laboratories, Abbott Park, Illinois,

USA; ${ }^{4}$ Abbott Scandinavia AB, Solna, Sweden; ${ }^{5}$ Lorimer Enterprises Inc; ${ }^{6}$ Department of Paediatrics, Alberta Children's Hospital, Calgary, Alberta Correspondence: Dr Philip Jacobs, Department of Medicine, University of Alberta, IHE, \#1200-10405 Jasper Avenue, Edmonton, Alberta T5J 3N4.

Telephone 780-448-4881, fax 780-448-0018, e-mail pjacobs@ihe.ca 
their study involving an outbreak of NRSV at the Royal Liverpool Children's Hospital-Alder Hey (Liverpool, United Kingdom) pediatric ICU, Thorburn et al (9) noted that 73\% (11 of 15) of the patients who developed an RSV infection had at least one of the following comorbidities: congenital heart disease, chronic lung disease, airway abnormalities or immunosuppression.

NRSV is considered to be preventable. In 2000, Zoutman et al (10) surveyed Canadian hospitals with $>80$ acute beds to assess infection surveillance and control activities. Results from 172 hospitals (72\% of total) identified deficits in key components of effective infection-control programs, which led the authors to conclude that greater investment in resources was required to meet recommended standards. The abovementioned study, however, did not examine the resources required to achieve reductions in NRSVs, or the expected impact of these preventive efforts.

The goal of the present study was to develop an economic model of pediatric RSV infection costs related to admissions for CRSV, infection-control measures and their costs, and additional treatment costs of NRSV cases.

\section{METHODS}

\section{Cost model}

The target variable of the model was the average cost of activities related to the treatment and infection control of RSV infection in hospital. The model was expressed in terms of the average confirmed CRSV hospital admission. The model explicitly included costs related to the treatment of CRSV cases, infection-control activities and the treatment of nosocomial infections that were secondary to a CRSV hospital admission (Table 1).

The variable average cost of a CRSV hospital admission $\left(\mathrm{C}_{\mathrm{r}}\right)$ in Table 1 represents all hospital and physician costs related to the treatment of a CRSV admission, and implicitly includes the cost of treating patients who require treatment within ICUs. $\mathrm{C}_{\mathrm{r}}$ was based on the product of the average Alberta (Canada) per diem cost for a case mix group related to respiratory infections and inflammations (11) and the average length of stay (ALOS) of CRSV hospital admissions $(12,13)$. Associated physician costs were estimated based on the Alberta medical fee schedule (14).

Intensive infection-control activities are performed in Canadian pediatric wards and/or hospitals when RSV infection cases are detected, resulting in a reduced number of nosocomial cases than would have otherwise occured. Infection control includes strict hygiene, isolation of infected patients, diagnostic testing, and education for staff members and parents. The infection-control cost variable $\left(\mathrm{C}_{\mathrm{ic}}\right)$ included the average costs of all diagnostic testing per CRSV case as well as costs related to contact isolation including supplies (gloves and gowns) and administration costs (nursing salaries and benefits). The estimates for all cost variables related to infection control involved with a CRSV admission were derived from a 1996 US study by Macartney et al (15), which reported the results of an implemented infection-control protocol; the patient numbers from the study by Macartney et al were used to obtain average prevention costs. The average cost of diagnostic testing was estimated as the product of the unit cost of an RSV test and the average number of all RSV tests undertaken (including negative results) per CRSV admission. Supply costs were estimated as the product of reported per diem supply costs and the estimated Canadian ALOS for CRSV. It should be noted that a small portion of infection-control costs are semi-fixed and hospitalwide and, as such, were considered to be variable.

For each CRSV, there is a probability that the infection will be transmitted to patients who were not infected with RSV and that a nosocomial case will occur. The resulting NRSV contributes to a longer stay and greater cost. The average cost of treating nosocomial cases per CRSV admission variable $\left(\mathrm{C}_{n}\right)$, was calculated as the product of the estimated cost of treating a single NRSV case and the rate of transmission. This additional cost per case of NRSV was derived by multiplying $\mathrm{C}_{\mathrm{r}}$ by an estimated ratio of the additional cost of treating NRSV cases to the cost of a CRSV admission $(11,16)$.
TABLE 1

Formula for the average cost of treating a nosocomial respiratory syncytial virus infection (NRSV)

\begin{tabular}{ll}
\hline \multicolumn{4}{l}{ Average cost $=\mathrm{C}_{\mathrm{r}}+\mathrm{C}_{\mathrm{ic}}+\mathrm{C}_{\mathrm{n}}$} \\
\hline $\mathrm{C}_{\mathrm{r}} \quad$ Average cost of CRSV hospital admission \\
$\mathrm{C}_{\mathrm{ic}} \quad$ Average cost of infection-control activities (per CRSV) \\
$\mathrm{C}_{\mathrm{n}} \quad$ Average additional cost (per CRSV) of treating NRSVs \\
\hline CRSV Community-acquired respiratory syncytial virus infection
\end{tabular}

To avoid mixing US and Canadian cost data, the nosocomial cost ratio was calculated using a ratio of two ratios. The numerator was an estimate of the additional cost (US\$) to treat a NRSV divided by the cost of a typical hospital case (3.12) (16). The denominator was $\mathrm{C}_{\mathrm{r}}$ (Canadian\$) divided by the cost of a typical hospital case $(0.78)$ (11). The resulting ratio provides an estimate of the additional cost of treating a NRSV case compared with the cost of treating a CRSV admission alone $(4.0=3.12 / 0.78)$.

The rate of transmission, defined as the expected number of NRSV admissions per CRSV admissions, was estimated to be $6.1 \%$ from results reported by Simon et al (7) from a study involving German hospitals. The rate of $6.1 \%$ is similar to a previous Canadian estimate of $6.4 \%$ (17).

The model presented in the present study reflects a balance between the increase in infection-control costs and the reduction in nosocomial cases and associated costs. All costs were estimated in 2007/2008 Canadian dollars. Prevention costs were adjusted to 2007/2008 prices using a US all-items price index (18) and converted to Canadian dollars using the purchasing power parity method (19). All other costs, already in Canadian dollars, were adjusted to the reference year using the all-items Canadian consumer price index (20).

Deterministic sensitivity analyses

Three sensitivity analyses were undertaken. A tornado analysis was performed in which four key variables (ALOS, hospital inpatient cost, NRSV cost ratio and transmission rate) were varied equally by $\pm 10 \%$ to assess their relative impact on average cost.

A second analysis explicitly accounted for the proportion of CRSV patients admitted to the ICU and the relatively higher cost of treatment within an ICU unit. Randolph et al (21) reported that 7.4\% of CRSV patients admitted to hospital were subsequently admitted to the ICU and had an ALOS of 8.6 days; four days on the pediatric ward and 4.6 days in the ICU (21). A recent Canadian study reported that the ICU per diem cost $(\$ 2,335)$ was approximately 2.5 times greater than the pediatric ward cost (\$957) (22). These data were used to re-estimate the overall cost of a CRSV admission, including infection prevention and nosocomial treatment costs.

The final deterministic analysis assessed the impact of infection control on average cost. Previous research has shown that an active prevention and infection-control program resulted in a 39\% reduction in nosocomial cases (15). Conversely, this implies that the transmission rate in the absence of prevention would be $64 \%(1 /[1-0.39])$ higher than the rate following the adoption of infection-control practices. Thus, in the absence of an infection-control policy, it was assumed that the expected transmission rate would increase to $10.5 \%$, compared with $6.1 \%$ with infection control.

\section{Probabilistic sensitivity analysis}

Using Monte Carlo simulation, a probabilistic sensitivity analysis (PSA) was performed to simultaneously assess the uncertainty related to all estimates used in the model. This analysis, based on 5000 replications, provided a 95\% CI for average cost. For all variables, except hospital inpatient cost, a triangular distribution was used because estimates of SD were unavailable. Because the estimates were based on source studies with large samples $(\mathrm{n} \geq 100)$ or large administrative databases, it appeared reasonable to specify a maximum/minimum range of $\pm 10 \%$ from the mean. For the nosocomial cost ratio, a range of $\pm 50 \%$ was used to reflect the greater variability expected, because this variable was derived from two other ratios. Because hospital inpatient cost 
TABLE 2

Extrapolation of nosocomial respiratory syncytial virus infection (NRSV) cost to the national level

\begin{tabular}{lr}
\hline Variable & \\
\hline 1. Canadian population younger than one year of age, & $400,000.00$ \\
2009 [21], $\mathrm{n}$ & \\
2. CRSV admission rate per year per 100,000 persons [5] & 2000.00 \\
3. Total annual CRSV admissions $=(1) \times(2) / 100,000$ & 8000.00 \\
4. Cost of treating NRSV per CRSV admission (\$CAN) & $\$ 993.00$ \\
5. Annual NRSV cost (\$CAN) & $\$ 7,944,000.00$ \\
\hline
\end{tabular}

Numbers in square brackets refer to references. \$CAN 2007/2008 Canadian dollars; CRSV Community-acquired respiratory syncytial virus infection

was such an important variable in the model, a gamma distribution was used to reflect the skewed distribution expected for cost variables.

Extrapolation of NRSV costs to the national level

To estimate the national burden of NRSV, the estimated $C_{n}$ was extrapolated to the Canadian pediatric population $<1$ year of age (23). The estimated Canadian RSV hospitalization rate for children $<6$ months of age was applied to this population to estimate the number of annual CRSV admissions (5). The annual economic burden of treating NRSVs was estimated by multiplying the number of reported cases of NRSV by the $\mathrm{C}_{\mathrm{n}}$ estimate (\$993). This method is summarized in Table 2.

Excel 2004 (Microsoft Corporation, USA) was used for all calculations, except the PSA, which was performed using the TreeAge Pro Healthcare Module 2009 (TreeAge Software Inc, USA).
Base-case analysis (Table 3)

\section{RESULTS}

$\mathrm{C}_{\mathrm{r}}$ was $\$ 4,069$, based on the per diem cost of $\$ 1,287$ (after adjustment for inflation), an inpatient ALOS of three days and $\$ 207$ of physician fees.

$\mathrm{C}_{\text {ic }}$ was $\$ 247$ per CRSV case, which included an average cost of $\$ 196$ for diagnostic testing, $\$ 32$ for the cost of supplies and $\$ 19$ for administration over the three-day ALOS.

$\mathrm{C}_{\mathrm{n}}$ was four times $\mathrm{C}_{\mathrm{r}}(\$ 4,069)$, or $\$ 16,276$ per case. The rate of transmission of NRSV was found by Simon et al (12) to be $6.1 \%$ of CRSV hospitalizations; multiplying the total additional costs by this rate produces a $C_{n}$ of $\$ 993$. Thus, $C_{i c}$ and $C_{n}$ added approximately $30.5 \%$ to the inpatient cost of each CRSV case, bringing the total average per case cost of treating an RSV hospital admission up to $\$ 5,309$, from $\$ 4,069$.

Deterministic sensitivity analyses

The tornado analysis (Figure 1) determined the relative impact of four key input variables on the overall average cost when they were varied by an identical percentage. The variations in the estimates of ALOS and inpatient cost per day had the greatest impact, because the cost of the CRSV admission was the major component in the overall average cost. The nosocomial cost ratio and the transmission rate had a modest impact on the overall average cost.

The second sensitivity analysis explicitly accounted for the proportion of CRSV patients admitted to the ICU, the higher average length of stay of those patients and the relatively higher per diem cost associated with the ICU unit. The result of these changes was an overall average cost of $\$ 5,155$ per CRSV admission, which was only approximately $3 \%$ less than the base-case analysis, indicating that the basecase analysis was reasonably robust.

\section{TABLE 3}

Component variables involved in treatment of community-acquired respiratory syncytial virus infection (CRSV) and nosocomial respiratory syncytial virus infection (NRSV) and infection-control measures (base case)

\begin{tabular}{|c|c|c|}
\hline Variable & Value & Data source \\
\hline \multicolumn{3}{|c|}{ Cost of a CRSV hospital admission, $\mathrm{C}_{\mathrm{r}}$} \\
\hline CRSV ALOS, days & 3 & $(12),(13)$ \\
\hline \multirow{3}{*}{$\begin{array}{l}\text { Hospital inpatient cost per } \\
\text { CRSV admission }\end{array}$} & $\$ 3,862$ & Cost per day $\times$ ALOS $=\$ 1,287.38 \times 3$ days \\
\hline & & Cost per day derived from a case mix group involving 137 respiratory infections and inflammations (11) \\
\hline & & $\$ 11,800(2005 / 2006$ \$CAN)/10 ALOS = \$1,180 per day + inflation adjustment $(9.1 \%)(20)$ \\
\hline \multirow[t]{2}{*}{ Physician component } & $\$ 207$ & Alberta Health Care Insurance Plan, Medical Price List (April 1, 2007) (14) \\
\hline & & Each added day: Fee code 0303D PEDNH2 (\$38.79) for two days \\
\hline
\end{tabular}

Subtotal
Cost of infection-control activities, $\mathbf{C}_{\text {ic }}$
Average cost of diagnostic tests
per CRSV case

Average cost of prevention supplies per CRSV case

Administrative costs for preventive $\$ 19$ program, per CRSV case

Subtotal

Additional cost (per CRSV) of treating NRSV cases, $C_{n}$

Nosocomial cost ratio

$\Delta$ cost (NRSV) / $\Delta$ cost (CRSV)

Additional costs of treating an NRSV case

Rate of transmission of RSV

infections, \%

Subtotal

Average cost per CRSV

admission

Data presented as 2007/2008 Canadian dollars (\$CAN) unless otherwise indicated. Numbers in parantheses refer to references. ALOS Average length of stay; US United States
Diagnostic tests per CRSV admission $\times$ unit cost $=6.31 \times \$ 31.06$

Tests per CRSV admission (including negative results) $=3255$ tests per year/516.25 RSV admissions per year $=6.31(15)$ Unit cost per tests $=\$ 19.17$ (15) adjusted by $62 \%$ for inflation (18) and purchasing power parity (19)

$\$ 32$ Supply cost per day $\times$ ALOS $=\$ 10.72 \times 3$

Cost of gloves and gowns = $\$ 6.62$ per day (15) adjusted by $62 \%$ for inflation (18) and purchasing power parity (19)

Administrative cost per program $=\$ 6,000$ total cost (15)/516.25 admissions per year (15) adjusted by $62 \%$ for inflation (18) and purchasing power parity (19)

4.0 Ratio $=3.12 / 0.78$

Cost of an NRSV (US) $=3.12$ times the cost of a typical hospital case (16)

The cost of a CRSV (Canada) $=0.78$ times the cost of a typical hospital case (Alberta, 2005/2006) (11)

$\$ 16,276 \quad C_{r} \times$ nosocomial cost ratio $=\$ 4,069 \times 4.0$

6.1\% Rate $=$ NRSV cases/CRSV admissions $=90 / 1478(7)$

$\$ 993$

Additional cost of an NRSV $\times$ rate of transmission $=\$ 16,276 \times 0.061$ 


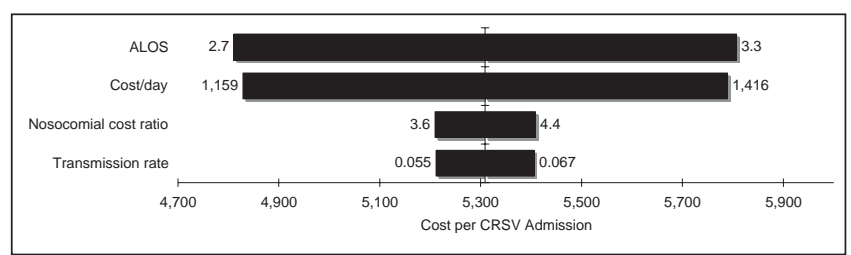

Figure 1) Tornado diagram illustrating $\pm 10 \%$ variation in input variables. ALOS Average length of stay; CRSV Community-acquired respiratory syncytial virus infection

In the final deterministic analysis, the transmission rate was increased to $10.5 \%$ to reflect what the rate may be if no infectioncontrol activities were undertaken. In the absence of a hospital-based RSV infection-control program, $\mathrm{C}_{\mathrm{n}}$ would increase by $\$ 716$ (14\%) per CRSV hospital admission. However, when $\mathrm{C}_{\mathrm{ic}}$ was deducted, the net increase in overall cost was $\$ 469$ per CRSV admission, or approximately $9 \%$. Conversely, this estimate would represent the average savings, per CRSV admission, due to infection-control activities.

\section{PSA}

The PSA produced a near normal distribution around the base-case result of $\$ 5,309$, providing a $95 \% \mathrm{CI}$ of $\$ 4,597$ to $\$ 6,097$, or approximately $\pm 14 \%$ (Table 4 ). This is a reasonably tight $95 \% \mathrm{CI}$; however, the interval is highly dependent on the dispersion of the sampling distributions of the input variables. The SE of many of the distributions was based on an assumption, which should be considered when evaluating the $95 \% \mathrm{CI}$.

\section{Extrapolation of $\mathrm{C}_{\mathrm{n}}$ to the national level}

In the base-case analysis $C_{n}$ was $\$ 993$. By multiplying this value by the projected number of RSV cases in the Canadian pediatric population $<1$ year of age, the cost to treat NRSV infections in the hospital setting was estimated to be approximately $\$ 7.9$ million per year (Table 2).

\section{DISCUSSION}

We estimated the full cost associated with pediatric CRSV hospital admissions, including the costs of the original CRSV cases, and the additional costs to prevent and treat NRSV cases. Using primarily Canadian data, we estimated that NRSV adds $\$ 993$ to each CSRV case; the original cost was approximately $\$ 4,000$. Using a sensitivity analysis, we estimated that infection-control procedures, costing $\$ 247$ per case, lead to a reduction in transmitted treatment costs of $\$ 469$.

Although a number of studies have estimated RSV-related costs, only one included transmitted cost estimates (15). We presented our analysis in the form of a model, which enabled estimates to be made in a variety of environments and situations. Furthermore, we applied a variety of sensitivity analyses, which add considerable confidence to our results. Many hospital planning departments do not collect data in the format that was used in the present study. However, most of the variables in our model are readily available from different departments in the hospital. These include RSV testing from the hospital infection control department, infection-control supplies from the hospital inventory, and length of stay and treatment costs from the hospital financial department. We took into consideration the best evidence available on respiratory infectious disease transmission rates and noted that the $6.1 \%$ applied in our model is within published ranges for nosocomial infection transmission (24-26).

Generally speaking, resource utilization rates and unit cost vary considerably among countries. We attempted to use Canadian cost data as much as possible to consistently reflect the cost experience of one jurisdiction. It was a limitation of the present study that we were unable to use Canadian cost data for all the input variables. Where it was necessary to use US data, we incorporated it into relative measures in as many instances as possible. When absolute data were used, we converted the US costs to Canadian costs using the purchasing power parity method (19).
TABLE 4

Simulation results for 5000 replications

\begin{tabular}{lc}
\hline Statistic & Cost of RSV \$ \\
\hline Cost, mean \pm SD & $5,312 \pm 380$ \\
Minimum value & 4,159 \\
2.5th percentile & 4,597 \\
10th percentile & 4,824 \\
Median & 5,310 \\
90th percentile & 5,808 \\
97.5th percentile & 6,079 \\
Maximum value & 6,896 \\
\hline
\end{tabular}

RSV Respiratory syncytial virus infection

A specific limitation of our estimate of $C_{i c}$ was that the source study we used did not include the use of masks in the infection prevention program, whereas the use of masks has become a standard component of more recent infection control protocols (9). Because the cost of masks would represent a very small additional amount, relative to the total cost per CRSV admission, we have not attempted to adjust the data obtained from our source study.

Most hospitals should have the data required to perform these basic cost-effectiveness calculations; those that do not can use the estimates that we provide. This, of course, will limit the applicability to a specific hospital. However, this is a very simple model, and should be well within the grasp of most infection-control and finance departments.

\section{CONCLUSION}

Results of our model indicated that the cost of treating NRSV infection significantly contributed to the overall cost of CRSV hospital care. Public health prevention strategies to reduce the prevalence of severe pediatric RSV infection should be considered and their impact on costs evaluated.

ACKNOWLEDGEMENTS: The authors acknowledge SNELL Medical Communication for their assistance with literature searches, manuscript editing and proofing. Writing and subsequent content revisions were performed entirely by the authors, who take full responsibility for the article.

DISCLOSURES: PJ, DL, ML and IM have a consulting relationship with Abbott Laboratories. KG and KB own stock in Abbott Laboratories.

\section{REFERENCES}

1. Karron RA. Respiratory syncytial virus and parainfluenza virus vaccines. In: Plotkin SA, Orenstein WA, Offit PA, eds. Vaccines, 5th edn. Philadelphia: Saunders-Elsevier 2008;1283-93.

2. Welliver RC, Checchia PA, Bauman JH, Fernandes AW, Mahadevia PJ, Hall CB. Fatality rates in published reports of RSV hospitalizations among high-risk and otherwise healthy children. Curr Med Res Opin 2010;26:2175-81.

3. Centers for Disease Control and Prevention. Respiratory syncytial virus activity - United States, July 2008-December 2009. Morb Mortal Wkly Rep 2010;59:230-3.

4. Langley JM, Wang EE, Law BJ, Stephens D, Boucher FD, Dobson S. Economic evaluation of respiratory syncytial virus infection in Canadian children: A Pediatric Investigators Collaborative Network on Infections in Canada (PICNIC) study. J Pediatr 1997;131:113-7.

5. Schanzer DL, Langley JM, Tam TW. Hospitalization attributable to influenza and other viral respiratory illnesses in Canadian children. Pediatr Infect Dis J 2006;25:795-800.

6. World Health Organization. Prevention of Hospital-acquired Infections: A Practical Guide, 2nd edn. Malta: World Health Organization Department of Communicable Disease. WHO/CDS/ CSR/EPH/2002.12.

7. Simon A, Müller A, Khurana K, et al; DSM RSV Paed Study Group. Nosocomial infection: A risk factor for a complicated course in children with respiratory syncytial virus infection - results from a 
prospective multicenter German surveillance study. Int J Hyg Environ Health 2008;211:241-50.

8. Grohskopf LA, Sinkowitz-Cochran RL, Garrett DO, et al; Pediatric Prevention Network. A national point-prevalence survey of pediatric intensive care unit-acquired infections in the United States. J Pediatr 2002;140:432-8.

9. Thorburn K, Kerr S, Taylor N, van Saene HK. RSV outbreak in a paediatric intensive care unit. J Hosp Infect 2004;57:194-201.

10. Zoutman DE, Ford D, Bryce E, et al; Canadian Hospital Epidemiology Committee; Canadian Nosocomial Infection Surveillance Program; Health Canada. The state of infection surveillance and control in Canadian acute care hospitals. Am J Infect Control 2003;31:266-73.

11. Alberta Health and Wellness. Alberta Case Cost Report For 2005/06 Hospital Activity. Annual Report. Edmonton: Government of Alberta, 2008.

12. Kuzik BA, Al-Qadhi SA, Kent S, et al. Nebulized hypertonic saline in the treatment of viral bronchiolitis in infants. J Pediatr 2007;151:266-70.

13. Hall CB, Weinberg GA, Iwane MK, et al. The burden of respiratory syncytial virus infection in young children. $\mathrm{N}$ Engl J Med 2009;360:588-98.

14. Alberta Health Care Insurance Plan. Schedule of Medical Benefits (Procedures and Price List). Edmonton: Government of Alberta, 2007.

15. Macartney KK, Gorelick MH, Manning ML, Hodinka RL, Bell LM. Nosocomial respiratory syncytial virus infections: The costeffectiveness and cost-benefit of infection control. Pediatrics 2000;106:520-6.

16. Kilgore ML, Ghosh K, Beavers CM, Wong DY, Hymel PA Jr, Brossette SE. The costs of hospital-acquired infections. Med Care 2008;46:101-4.

17. Langley JM, LeBlanc JC, Wang EE, et al. Nosocomial respiratory syncytial virus infection in Canadian pediatric hospitals: A pediatric investigators collaborative network on infections in Canada (PICNIC) study. Pediatrics 1997;100:943-6.

18. Bureau of Labor Statistics. Consumer Price Index: All Urban Consumers - (CPI-U). All Items Indexes and Annual Percent Changes From 1913 to Present. Washington, DC: US Department of Labor, 2011.

19. OECD. StatExtracts. Monthly Comparative Price Levels. Paris: Organisation for Economic Co-operation and Development, 2011.

20. Statistics Canada. The Consumer Price Index (62-001-XWE). Ottawa: Statistics Canada, 2010.

21. Randolph AG, Reder L, Englund JA. Risk of bacterial infection in previously healthy respiratory syncytial virus-infected young children admitted to the intensive care unit. Pediatr Infect Dis J 2004;23:990-4.

22. Lanctôt KL, Masoud ST, Paes BA, et al. The cost-effectiveness of palivizumab for respiratory syncytial virus prophylaxis in premature infants with a gestational age of 32-35 weeks: A Canadian-based analysis. Curr Med Res Opin 2008;24:3223-37.

23. Statistics Canada. Estimates of Population, by Age Group and Sex for July 1, Canada, Provinces and Territories (Table 051-0001). Ottawa: Statistics Canada, 2009.

24. Madge P, Paton JY, McColl JH, Mackie PLK. Prospective controlled study of four infection-control procedures to prevent nosocomial infection with respiratory syncytial virus. Lancet 1992;340:1079-83.

25. World Health Organization. Prevention of Hospital-Acquired Infections: A Practical Guide. World Health Organization Department of Communicable Disease. WHO/CDS/CSR/ $\mathrm{EPH} / 2002.12$

26. Goldman DA. Epidemiology and prevention of pediatric viral respiratory infections in health-care institutions. Emerg Infect Dis 2001;7:249-53. 


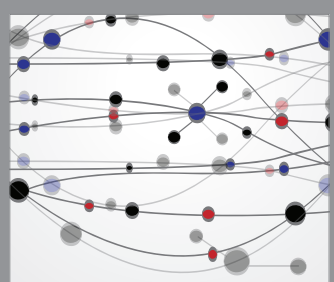

The Scientific World Journal
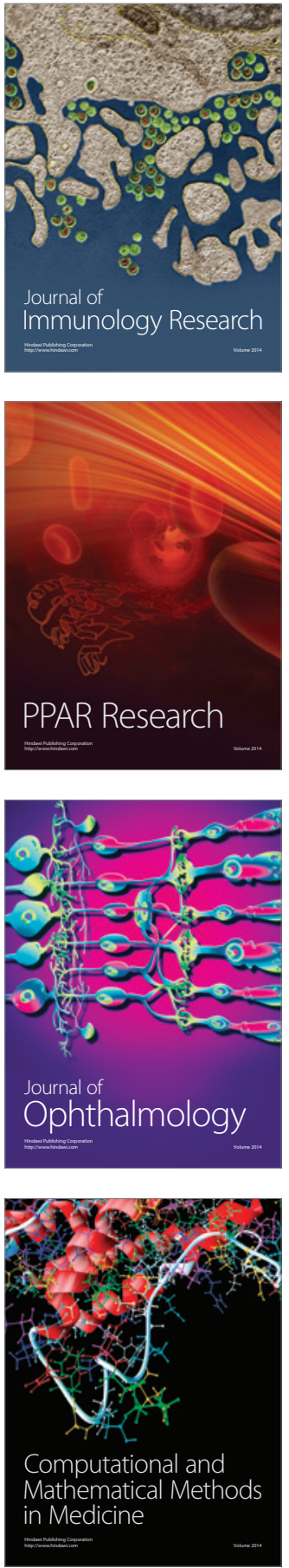

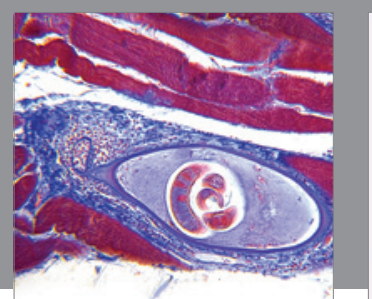

Gastroenterology Research and Practice

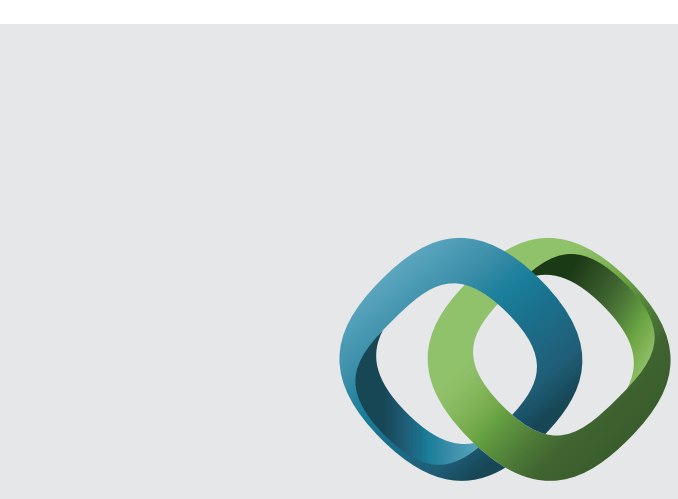

\section{Hindawi}

Submit your manuscripts at

http://www.hindawi.com
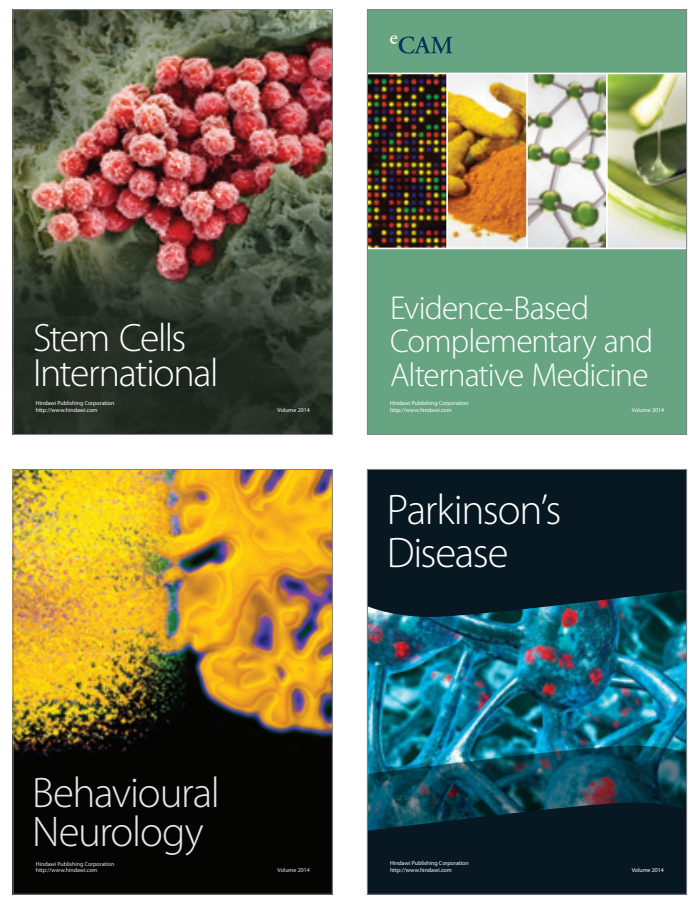
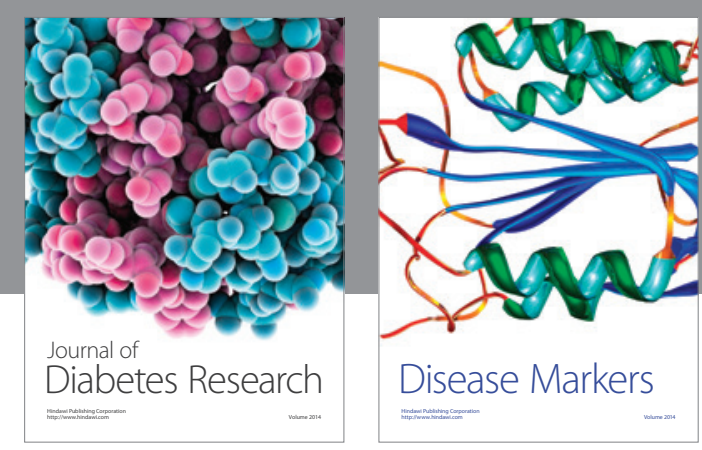

Disease Markers
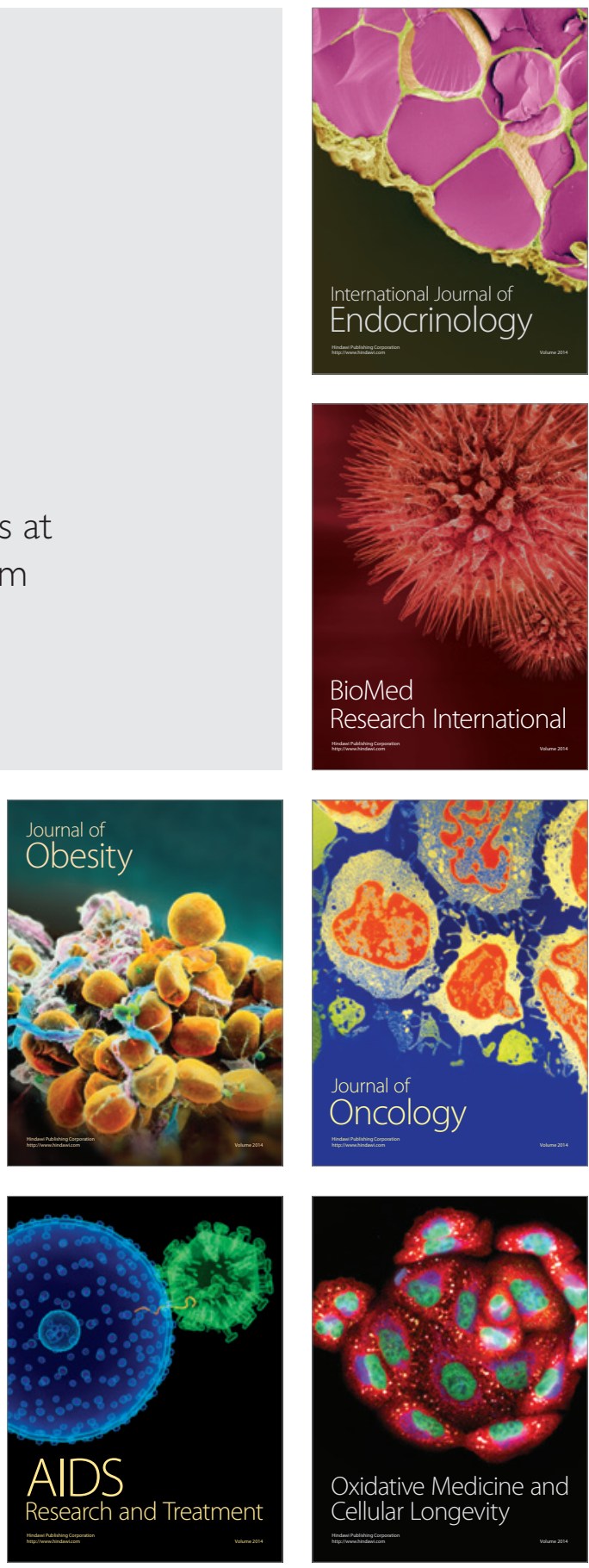